\title{
ALLELOCHEMICS: AN INTERACTION BETWEEN PHYTOPHAGES AND Pseudomonas syringae pv. tomato ON TOMATO Solanum lycopersicum PLANTS
}

\section{E.A. STEPANYCHEVA, M.O. PETROVA, A.V. SHCHENIKOVA, T.D. CHERMENSKAYA}

\author{
All-Russian Research Institute of Plant Protection, Federal Agency of Scientific Organizations, 3, sh. Podbel'skogo, \\ St. Petersburg, 196608 Russia, e-mail stepanycheva@yandex.ru, tchermenskaya@yandex.ru \\ Acknowledgements: \\ The authors thank Prof. E.I. Savel'eva (Research Institute of Hygiene, Occupational Pathology and Ecology, the \\ Federal Medical and Biological Agency) for carrying out chemical analysis of volatile compounds \\ Received February 19, 2016
}

\section{Abstract}

Until recently, induced resistance to pathogens and phytophages considered separately and only in recent years the attention are being paid to the possibility of an induced cross-resistance. The aim of this work was to study the nature of the chemical interaction between plants and phytopathogenic microorganisms and arthropods phytophages, inhabiting the same ecological niche. The possibility of mutually-modifying effects of phytophagous and pathogens on quantitative and qualitative indicators of the defense response of tomato plants were shown. As the first order consumers the Western flower thrips Frankliniella occidentalis and whitefly Trialeurodes vaporariorum were chosen as most dangerous herbivores of greenhouse crops, and Pseudomonas syringae pv. tomato, a bacterial pathogen of tomato mottle, was used. The evaluation criteria were the changes in behavioral responses of herbivores and their demographic parameteres, and for pathogen the degree of infection development was expressed in points. Under the insects' free choice, the tomato plants previously infected with $P$. syringae, were more preferable by thrips, while remained not more attractive for whitefly. Attraction of thrips to infected plants may be due to the appearance and increasing content of volatile substances such as 2-methylbutanoic acid and dodecane, which are components of the thrips pheromone and allomons. Under the primary damage of plants by thrips and whitefly the further pathogen development differed (e.g., the thrips suppressed the disease, while the whitefly served as promoters for its development). Inhibition of the pathogen on plants damaged by thrips, may be due to an increase in the content of these chemical compounds, such as, for example, (E)- $\beta$-ocimene and $\alpha$-humulene that are part of many essential oils and plant extracts with antimicrobial activity. The content of these same substances was increased in plants in response to inoculation with the pathogen. The results indicate both the differences and similarities of some signaling pathways and mechanisms of defense reaction in plants in response to induction phytophagous or phytopathogens. It identified the induced resistance and partial antagonism (down to completely opposite effect - the reduction of plant resistance) with respect to a group of consumers. A thorough assessment of the nature of these responses, its biochemical and molecular genetic basis will contribute to the strategy of environment-friendly plant protection.

Keywords: western flower thrips, greenhouse whitefly, induced defense, Pseudomonas syringae

One of generally acknowledged approaches to introduction of environmental science into plant growing is decreasing pesticide load on agrobiocenosis. This is associated with more thorough research of plants' adaptive potential including resistance to main biotic and abiotic stressors. In order to choose appropriate plant variety, it is necessary to enhance plant defense response, particularly to induce a non-specific resistance. There is good evidence of general defense mechanisms which are known as acquired immunity providing resistance under repeated infection. Induced resistance can be both local and systemic. It can manifest itself in plant parts and organs which are distant from the primary infection site. This phenomenon, deeply investigated in plant-phytopathogen system, includes activation of protection genes and metabolic changes which are detrimental to pathogen. A systemic cross-resistance against fungal, bacterial, and viral pathogens is shown to occur after preceding or concurrent contact with related 
and unrelated agents [1, 2].

Analogous increase in resistance against phytophages after damage caused by conspecific or heterospecific arthropods species was observed well after [3]. Currently, there is massive evidence in favor of involvement of different protective mechanisms in these processes [4-6]. Induction of volatile compounds is important fast reaction in plants to damage caused by phytophages. These compounds (e.g. repellents, deterrents, etc.) play important role in complex interactions between different trophic levels [7, 8]. Some substances that provide induced plant resistance were chemically analyzed and identified. Such substances are not directly toxic to injurious object and render protective effect through regulatory mechanisms [9-12].

Until recently, induced resistance to pathogens and phytophages considered separately, and only in recent years the attention is being paid to the possibility of an induced cross-resistance. There is contradictory information about mutual influence of changes induced by phytophages or phytopathogens to organisms of the same biotope [13-16].

For the fist time, we studied a nature of plant response to simultaneous impact of multiple damaging agents with different damage localization and different damaging mechanisms.

The aim of this work was to study chemical interaction of plants with phytopathogenic microorganisms and arthropods phytophages as different level consumers in the same ecological niche.

Techniques. Tomato (Solanum lycopersicum L.) Belyi Naliv cultivar (sensitive) plants were individually grown in plastic cups at $24-26{ }^{\circ} \mathrm{C}$ with regular watering and complex fertilizing. Western flower thrips Frankliniella occidentalis and whitefly Trialeurodes vaporariorum were chosen as most dangerous herbivores of greenhouse crops, and Pseudomonas syringae pv. tomato (bacterial agent of tomato mottle, obtained from Russian State Agrarian UniversityK.A. Timiryazev Moscow Agricultural Academy) was a phytopathogen. The same objects were used as inducers.

In order to evaluate the response to phytopathogen, the tomato plants at a stage of 3-4 true leaves were inoculated with $P$. syringe $\left(10^{6}\right.$ cells $/ \mathrm{ml}$, two lower true leaves were scratched with sand and then treated with pathogen suspension). Control plants were sprayed by water after damaging. Later, the plants with 5-6 true leaves and damage of 2.2-2.5 points (using 5-point scale) were used. Before the experiment, 2 lower damaged leaves were removed in all infected and intact plants. The plants prepared in such a manner were placed into glass cylinders $(5$ L) pairwise (test+control). Female Western flower thrips or whitefly imagos were put in these cylinders (30 insects per plant). Distribution of insects among the plants was counted 2 days after. After imago removal, the tomato plants were placed into isolated boxes to prevent repeated attack. Next generation thrips were counted after emergence of larvae, whiteflies were counted after appearance of second instar larvae. Response effectiveness was evaluated on the basis of number of phytophage offspring.

To examine the influence of the Western flower thrips or whitefly on a course of the disease, the plants were individually placed into glass cylinders with adult insects (30 insects per plant). One day after (two days for the whitefly), imagos were removed and the plants were left for 5 or 7 days to allow larvae of the Western flower thrips and the whitefly, respectively, to inflict damage (the

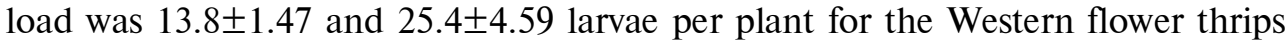
and the whitefly, respectively). After larvae counting (in case of thrips the larvae were further removed $), P$. syringe $\left(10^{6}\right.$ cells $\left./ \mathrm{ml}\right)$ was applied to damaged and intact plants. In control plants, upper leaves were pre-scratched with sand. Leaf 
damage was evaluated 7 days after the inoculation.

Volatile substances were extracted from upper tomato leaves. The leaves were milled, and samples ( $1 \mathrm{~g})$ were placed into $50 \mathrm{ml}$ a conical flask to which hexane was added up to upper edge of plant material. Extraction was performed by sonication in ultrasound bath Grad 13-35 (OOO Grad-Technology, Russia) for 15 minutes. After decantation the extracts were filtered through anhydrous sodium sulfate. Hexane was distilled in vacuum at $35^{\circ} \mathrm{C}$, and extract was concentrated to $500 \mu \mathrm{l}$ under nitrogen and stored at $-18^{\circ} \mathrm{C}$.

Samples were analyzed by gas chromatography-mass spectrometry (GCMS) using a GCMS-QP5000 complex (Shimadzu Corp., Japan). Components were identified by comparison of retention times in their mass spectra to reference values. Specifications of gas chromatographic separation: $250{ }^{\circ} \mathrm{C}$ as solvent temperature; sample injection without flow separation $(0.2 \mathrm{~min})$; initial temperature of column (DB-5) $40^{\circ} \mathrm{C}$, temperature increase rate $10{ }^{\circ} \mathrm{C} / \mathrm{min}$, final temperature of column $270^{\circ} \mathrm{C}$, exposure at final temperature 15 мин; carrier gas helium with flow velocity $1 \mathrm{~mm}^{3} / \mathrm{min}$; interface and detector temperature $280^{\circ} \mathrm{C}$. Specifications of mass spectrometry: ionizing electron energy $70 \mathrm{eV}$, interface and ion source temperature $280^{\circ} \mathrm{C}$, TIC (total ion current) identification.

Tests were performed in 10 replicates. Each test data were analyzed using ANOVA. Differences were considered significant at $\mathrm{P} \leq 0.05$.

Results. Evaluation criteria for phytophage were behavioral changes and demographic parameters (as the insects can refuse to eat or lay eggs on the plant due to plant defense reaction). For pathogen, the infection development was used as a parameter.

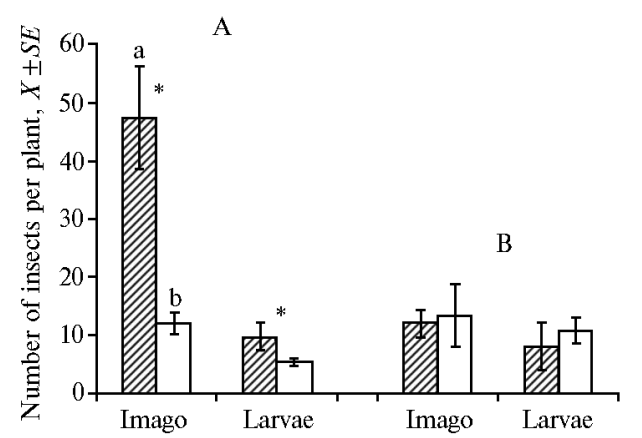

Fig. 1. Behavior of the Western flower thrips Frankliniella occidentalis Pergande (A) and the whitefly Trialeurodes vaporariorum Westwood (B) on plants of tomato (Solanum lycopersicum L.) sensitive cultivar Belyi Naliv infected by Pseudomonas syringae: a - test group, b - control group. Total sample number -600 , number of replications 10. The data significant at $P \leq 0.05$ are marked with asterisk (laboratory tests).
Tests of defense response in tomato plants to phytopathogen revealed that female Western flower thrips preferentially ate and laid eggs on phytopathogen-infected plants, when free choice. Number of adult thrips on infected plants was 3.0 times higher than that in control group. Such distribution of female insects resulted in offspring size (1.8 times higher than that in control group). However, in whiteflies, there were no significant differences in attractiveness to imago or in offspring size (Fig. 1).

$P$. syringae infection resulted in production of 2,2-dimethylheptane, 2methylbutanoic acid, 3-methyloctane, dodecane, stearic acid. Content of 1,4dimethylcyclohexane, (E)- $\beta$-ocimene and $\alpha$-humulene increased 2.0-fold, butyl isobutyl phthalate and dibutyl phthalate content increased 2.6-fold and 8.7-fold, respectively, as compared to control, linalool, palmitine acid and linolenoic acid were 1.3 times higher.

Study of influence of primary damage of the tomato plants by Western flower thrips larvae and imago on disease development revealed systemic induced resistance. Average weighed score infection for upper leaves on the plants damaged by phytopphages was 3.0 times lower than that in control plants. On the contrary, the whitefly did not act as resistance inducer in tomato: test group showed significant 1.8-fold increase in damage score (Fig. 2). 
Damage by the thrips resulted in 2.0-fold $\beta$-ocimene and $\alpha$-humulene level, 1.7-fold $\alpha$-terpinene level, 1.2-fold sabinene level, more than 5-fold diethyl phthalate and diisooctyl phthalate levels, 2.0-fold 9-octadecenol level, and 1.2-fold diisobutyl phthalate, dibuthyl sebacinate, dibutyl phthalate levels as compared to control. Damage by the whitefly resulted in production of cymene, myrcene, methyl salycilate and an increased content of $\alpha$-pinene.

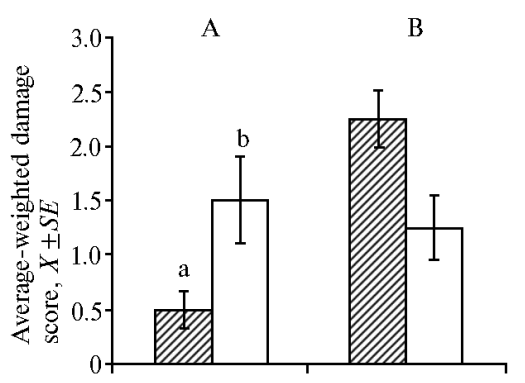

Fig. 2. Pseudomonas syringae infection in the plants of tomato (Solanum lycopersicum L.) sensitive cultivar Belyi Naliv damaged by the Western flower thrips Frankliniella occidentalis Pergande (A) and he whitefly Trialeurodes vaporariorum Westwood (B): a - test group, b - control group. Total sample number -600 , number of replications -10 . The data significant at $\mathrm{P} \leq 0.05$ are marked with asterisk (laboratory tests).

It should be noted that the plants face different external factors during vegetation. These factors induce wide range of both synergetic and anatagonistic responces. Due to this fact, studying the nature of such response under interaction with several groups of heterotrophic consumers (arthropods phytophages and pathogenic microorganisms) in the same trophic niche is of great interest. Moreover, sequential or concurrent attacks of phytophages and infectious agents are commonly observed. This causes the necessity to study mutual effects of these agents.

Analysis of publications indicates possible mutual modifying effects of phytophages and phytopathogens on quantitative and qualitative characteristics of defense response in plants. It is reported that damage by thrips and aphid prevents plants from development of fungus Colletotrichum orbiculare [17], and green dock leaf beetle Gastrophysa viridula can induce plant resistance to phytopatogens Ramularia rubella and Venturia rumicis [14]. In Arabidopsis thaliana damaged by larvae Pieris rapae, a significantly higher resistance was found to bacterial pathogens $P$. syringae pv. tomato and Xanthomonas campestris pv. armoraciae, but not to fungal pathogen Alternaria brassicicola [18]. In tomato, larvae Helicoverpa zea negatively affect both larvae (in case of repeated attack) and $P$. syringae pv. tomato. Moreover, in the same tomato plants the inoculation with $P$. syringae causes systemic induced resistance against both conspecific pathogen species and moth species $H$. zea and Spodoptera exigua. Unlike, tomato mosaic disease promoted body weight gain in larvae $S$. exigua, though inhibited proliferation of aphid Myzus persicae, therefore, its effects on the phytophages with different feeding habits were opposite $[16,19]$.

Pathogen inhibiting on plants damaged by thrips, may be due to an increase in the content of certain chemical compounds. (E)- $\beta$-ocimene and $\alpha$-humulene are components of many essential oils and plant extracts with antimicrobial activity [20- 22]. Terpenoid $\alpha$-terpinene significantly inhibits growth of fungi Sporothrix and Ceratocystis minor [23]. Sabinene possesses antimicrobial activity [24, 25]. Diethyl phthalate inhibits growth of Rhizobium vitis and Bacillus subtilis [26]. Other ethers of phthalic acid demonstrate significant antibacterial and antifungal activity against three gram-positive and two gram-negative bacteria and three pathogenic fungi [27].

It is more difficult to interpret the results of chemical analysis for the plants damaged by whitefly, where $P$. syringae infection score is significantly higher than that in control group. Probably, the amount of secreted substances is of importance. Despite antimicrobial activity of monoterpens, 50 and $150 \mathrm{ppm}$ o-cymene promotes growth of certain oomycetes [28].

Accumulated data indicate that biological inductors can significantly change plant metabolism resulting in increasing production of secondary me- 
tabolites secreted by intact plants or in de novo synthesis of protective substances (volatile or extractable compounds) which were not previously produced. Probably, each pathogen or phytophage species triggers different defense mechanisms and induce certain chemical reactions in plant.

In our experiments, the plants previously infected by $P$. syringae, were more preferable for thrips than intact ones, though both plant groups were equally attractive for whitefly. Under the primary damage of plants by thrips and whitefly the further pathogen development differed (the thrips suppressed the disease, while the whitefly could promote its development). Probably, it is associated with specific effects of the inductors (phytophages and phytopathogens) on target tissues that causes distinct responses manifested in unequal accumulation of previously secreted and newly synthesized substances.

Attraction of thrips to infected plants may be due to the synthesis and increasing content of some volatile substances. In fact, 2-methylbutanoic acid and dodecane are components of the thrips pheromone and allomons [29, 30]. Western flower thrips showed a significant electro-antennographic response to $\alpha$ humulen [31], and (E)- $\beta$-ocimene was determined as minor component with synergetic activity in composition of aggregated pheromone of this pest [32]. Thrips Cycadothrips chadwicki (Thysanoptera: Aeolothripidae) is attracted by (E)- $\beta-$ ocim-ene [33]. Linalool and linoleic acid are found in chrysanthemums, the food plants for the Western flower thrips, and linalool is said to be the substance that attracts the insect by its flavor [34, 35]. Dibutyl phthalate is characterized by slight fruit flavor that can attract insects, and butyl isobutyl phthalate is found in some flowering plants [36].

Summarizing data on chemical composition of the tomato plants allows us to reveal common pattern of damage caused by pathogen and the Western flower thrips. In both cases, there was significant increase in content of (E)- $\beta$ ocimene, $\alpha$-humulene and phthalates.

Thus, our results indicate both the differences and similarities of some signaling pathways and mechanisms of plant defense response to induction by phytophages or phytopathogens. We found both induced resistance and partial antagonism against a group of consumers, down to completely opposite effect of reducing plant resistance. Probably, plant response depends on taxonomic position of acting biotic agents and can be directed toward both conspecific and heterospecific species. A thorough study of induced defense reactions will give the opportunity to determine their ecological role and biochemical and molecular genetic mechanisms. It will contribute to the strategy of development of synthetic elicitors with different selectivity against certain biotic agent groups.

\section{REF E R E N C E S}

1. Duijff B.J., Pouhair D., Olivain C., Alabouvette C., Le manceau P. Implication of systemic induced resistance in the suppression of Fusarium wilt of tomato by Pseudomonas fluorescens WCS417r and by nonpathogenic Fusarium oxysporum Fo47. Eur. J. Plant Pathology, 1998, 104: 903-910.

2. Ran L.X., Li Z.N., Wu G.J., va n Loon L.C., B a k k e r P.A.H.M. Induction of systemic resistance against bacterial wilt in Eucalyptus urophylla by fluorescent Pseudomonas spp. Eur. J. Plant Pathology, 2005, 113: 59-70 (doi: 10.1007/s10658-005-0623-3).

3. Burov V.N., Pet rova M.O., S e litskaya O.G., S t e pany cheva E.A., C Her$\mathrm{m}$ e $\mathrm{n} \mathrm{s}$ k y a T.D., $\mathrm{S}$ h a $\mathrm{m} \mathrm{s}$ e v I.V. Indutsirovannaya ustoichivost' rastenii $k$ fitofagam. [Induced plant resistance to phytophags]. Moscow, 2012 (in Russ.).

4. Felto n G.W., Su m m e rs C.B., Mu e 11 e r A.J. Oxidative responses in soybean foliage to herbivory by bean leaf beetle and three cornered alfalfa hopper. J. Chem. Ecol., 1994, 20(3): 639-650 (doi: 10.1007/BF02059604).

5. Srinivas P., D a nie ls o n S.D., S mith C.M., F o st e r J.E. Cross-resistance and resistance longevity as induced by bean leaf beetle, Cerotoma trifurcate and soybean looper, Pseu- 
doplusia includens herbivory on soybean. J. Insect Sci., 2001, 1: 5.

6. Stepanycheva E.A., Chermenskaya T.D., Petrova M.O., Shchenikova A.V., B u rov V.N., S a v e l' e v a E.I. Evraziatskii entomologicheskii zhurnal, 2007, 6(1): 19-24 (in Russ.).

7. De Moraes C.M., Mes cher M.C., Tumlins o n J.H. Caterpillar-induced nocturnal plant volatiles repel conspecific females. Nature, 2001, 410: 577-580 (doi: 10.1038/35069058).

8. Delphia C.M., Mes cher M.C., De Moraes C.M. Induction of plant volatiles by herbivores with different feeding habits and the effects of induced defenses on host-plant selection by thrips. J. Chem. Ecol., 2007, 33(5): 997-1012 (doi: 10.1007/s10886-007-9273-6).

9. Y a lp a n i N., R a s k i n I. Salicylic acid: a systemic signal in induced plant disease resistance. Trends Microbiol., 1993, 1(3): 88-92 (doi: 10.1016/0966-842X(93)90113-6).

10. Sudhakar N., Nage ndra-Prasad D., Mohan N., Murugesan K. Induction of systemic resistance in Lycopersicon esculentum cv. PKM1 (tomato) against Cucumber mosaic virus by using ozone. J. Virol. Methods, 2007, 139(1): 71-77 (doi: 10.1016/j.jviromet.2006.09.013).

11. P o li k s e n o v a V.D. Vestnik Belorusskogo GU, 2009, 1: $48-60$ (in Russ.).

12. T y u t e r e v S.L. Mekhanizmy deistviya fungitsidov na fitopatogennye griby [Action of fungicides on fungal phytopathogens]. St. Petersburg, 2010 (in Russ.).

13. Mor a n P. Plant-mediated interactions between insects and a fungal plant pathogen and the role of plant chemical responses to infections. Oecologia, 1998, 115(4): 523-530 (doi: $10.1007 / \mathrm{s} 004420050550$ ).

14. H a t c h e r P.E., P a u 1 N.D. Beetle grazing reduces natural infection of Rumex obtusifolius by fungal pathogens. New Phytologist, 2000, 146: 325-333 (doi: 10.1046/j.1469-8137.2000.00646.x).

15. R o s t a s M., H i 1 k e r M. Asymmetric plant-mediated cross-effects between a herbivorous insect and a phytopathogenic fungus. Agr. Forest Entomol., 2002, 4(3): 223-231 (doi: 10.1046/j.1461-9563.2002.00147.x).

16. Thale r J.S., Agraw al A.A., H a lit s c h k e r R. Salicylate-mediated interactions between pathogens and herbivores. Ecology, 2010, 91(4): 1075-1082 (doi: 10.1890/08-2347.1).

17. Rus so V.M., Russo B.M., Peters M., Perkins-Veazie P., Cartwright B. Interaction of Colletotrichum orbiculare with thrips and aphid feeding on watermelon seedlings. Crop Protection, 1997, 16: 581-584 (doi: 10.1016/S0261-2194(97)00024-0).

18. De Vos M., Van Zaanen W.V., Koornneef A., Korzelius J.P., Dicke M., Van Loo n L.C., P i e t e rs e C.M.J. Herbivore-induced resistance against microbial pathogens in Arabidopsis. Plant Physiol., 2006, 142(1): 352-363 (doi: 10.1104/pp.106.083907).

19. S tout M.J., Fid a n t s ef A.L., Duffey S.S., B o s t o ck R.M. Signal interactions in pathogen and insect attack: systemic plant-mediated interactions between pathogens and herbivores of the tomato, Lycopersicon esculentum. Physiol. Mol. Plant P., 1999, 54(3-4): 115-130. (doi: 10.1006/pmpp.1998.0193).

20. Ed ris A.E., F a r r a g E.S. Antifungal activity of peppermint and sweet basil essential oils and their major aroma constituents on some plant pathogenic fungi from the vapor phase. Nahrung/Food, 2003, 47(2): 117-121 (doi: 10.1002/food.200390021).

21. Pitarokili D., Tzak ou O., Louk is A., H a rvala C. Volatile metabolites from Salvia fruticosa as antifungal agents in soilborne pathogens. J. Agric. Food Chem., 2003, 51: 32943301 (doi: $10.1021 /$ jf0211534).

22. Chorianopoulos N., Kalpoutzakis E., Aligiannis N., Mitaku S., Nyc has G.-J., Haroutounian S.A. Essential oils of Satureja, Origanum, and Thymus species: chemical composition and antibacterial activities against foodborne pathogens. J. Agric. Food Chem., 2004, 52: 8261-8267 (doi: 10.1021/jf049113i).

23. B ridge s J.R. Effects of terpenoid compounds on growth of symbiotic fungi associated with the southern pine beetle. Phytopathology, 1987, 77: 83-85 (doi: 10.1094/Phyto-77-83).

24. Glisik S.B., Milojevic S.Z., Dimitrijevic S.I., Orlovic A.M., Skala D.U. Antimicrobial activity of the essential oil and different fractions of Juniperus communis L. and a comparison with some commercial antibiotics. J. Serb. Chem. Soc., 2007, 72(4): 311-320 (doi: 10.2298/JSC0704311G).

25. Kohzaki K., Gomi K., Yamasaki-Kokudo Y., Ozawa R., Takabayashi J., Akimits u K. Characterization of a sabinene synthase gene from rough lemon (Citrus jambhiri). J. Plant Physiol., 2009, 166(15): 1700-1704 (doi: 10.1016/j.jplph.2009.04.003).

26. Is l a m M.T., A h n S.-Y., Cho S.-M., Y u n H.K. Isolation of antibacterial compounds from hairy vetch (Vicia villosa) against grapevine crown gall pathogen. Hortic. Environ. Biotechnol., 2013, 54(4): 338-345 (doi: 10.1007/s13580-013-0028-8).

27. Srinivasan G.V., S haranap a P., Le e la N.K., S a d a shiva C.T., Vijay a $\mathrm{n}$ K.K. Chemical composition and antimicrobial activity of Leea indica (Burm. f.) Merr. flowers. Nat. Prod. Radiance, 2009, 8: 488-493.

28. Camele I., Altieri L., De Martino L., De Feo V., Mancini E., Rana G.L. In vitro control of post-harvest fruit rots fungi by some plant essential oil components. Int. J. Mol. Sci., 2012, 13(2): 2290-2300 (doi: 10.3390/ijms13022290).

29. Suzuki T., Haga K., Kataoka M., Tsutsumi T., Nakano Y., Matsuya- 
m a S., Kuw a ha ra Y. Secretion of thrips VIII. Secretions of the two Ponticulothrips species (Thysanoptera: Phlaeothripidae). Appl. Entomol. Zool., 1995, 30: 509-519.

30. Suzuki T., Haga K., Tsutsumi T., Matsuy a ma S. Analysis of anal secretions from Phlaeothripine thrips. J. Chem. Ecol., 2004, 30: 409-423 (doi: 10.1023/B:JOEC.0000017985.89897.c3).

31. Abdullah Z.S., Ficken K.J., Greenfield B.P.J., Butt T.M. Innate responses to putative ancestral hosts: Is the attraction of western flower thrips to pine pollen a result of relict olfactory receptors? J. Chem. Ecol., 2014, 40: 534-540 (doi: 10.1007/s10886-014-0450-0).

32. Dublo n I.A.N. The aggregation pheromone of the western flower thrips. Thesis: Doctor of Philosophy by research (Ph.D.). Keele, Staffordshire, UK, 2009.

33. Terry I., Walte r G.H., Moore C., Roe mer R., Hull C. Odor-mediated push-pull pollination in Cycads. Science, 2007, 318: 70 (doi: 10.1126/science.1145147).

34. Le is s K.A., Maltes e F., Choi Y.H., Verpoorte R., Klinkhamer P.G.L. Identification of chlorogenic acid as a resistance factor for thrips in Chrysanthemum. Plant Physiol., 2009, 150: 1567-1575 (doi: 10.1104/pp.109.138131).

35. Yang T., Stoopen G., Thoen M., Wi e gers G., J o ng s m a M.A. Chrysanthemum expressing a linalool synthase gene 'smells good', but 'tastes bad' to western flower thrips. Plant Biotechnol. J., 2013, 11(7): 875-882 (doi: 10.1111/pbi.12080).

36. D a nilov D.A., Z y k ova I.D., E f re mov A.A. Uspekhi sovremennogo estestvoznaniya, 2013, 9: 156-158 (in Russ.). 